Carlos A. Scolari*

\title{
Transmedia branding: brands, narrative worlds, and the mcwhopper peace agreement
}

\author{
https://doi.org/10.1515/sem-2016-0216
}

\begin{abstract}
In recent years there has been much discussion about the links between brands and storytelling. This article briefly describes transmedia storytelling, reflects on some exemplary works to understand its cultural dynamics, and then focuses on one particular aspect: the development of transmedia strategies in branding. This article delves into that area where branding melts and recombines with storytelling, keeping an eye on transmedia worlds throughout. After presenting a semio-narratological analytical model the article applies the categories to Burger King's successful and internationally recognized McWhopper campaign (Campaign, Brief. 2015. Y\&R's Burger King “McWhopper” campaign: How a big idea from little New Zealand went global (interview to Tom Paine). Campaign Brief December 31. http://www.campaignbrief.com/ (accessed 16 October 2016)). The analysis spans from the construction of McWhopper's storytelling to the positioning of competitors in this particular transmedia narrative world. The article concludes with a series of reflections and recommendations for applying semio-narratologic categories to transmedia branding analysis and design.
\end{abstract}

Keywords: transmedia, storytelling, branding, transmedia worlds, narrative, user-generated contents

\section{Introduction}

Since the spread of personal computing in the 1980s and the emergence of the World Wide Web in the 1990s, digital technology has been a catalyst for socialtechnological change in contemporary societies. In this context the media ecology is currently undergoing a profound transformation from the traditional broadcasting system to the networking paradigm. When Henry Jenkins published in January 2003 an article in Technology Review titled "Transmedia

*Corresponding author: Carlos A. Scolari, Communication, Universitat Pompeu Fabra, Barcelona, Spain, E-mail: carlosalberto.scolari@upf.edu 
storytelling: Moving characters from books to films to video games can make them stronger and more compelling," nobody imagined that the concept of transmedia storytelling would become one of the favorite keywords of media professionals and researchers in the first decade of the new century. What started as a very personal reflection inspired by Jenkins' passion for fan cultures has become one of the key business strategies in the contemporary cultural industry and a central research object.

The main objectives of this article are:

- To describe transmedia storytelling and present its main connections with another form of narrative experience: branding. In this context, the article will introduce and define a new concept: "transmedia branding";

- To introduce a model for analyzing transmedia branding experiences that applies semiotic and narratological categories;

- To analyze a transmedia branding experience to test the usefulness of the proposed analytical model.

Section 2 focuses on transmedia storytelling, one of the most interesting phenomena currently emerging from the contemporary media ecology. The third section, dedicated to the relationships between branding and storytelling, defines "transmedia branding" and identifies its main traits. Section 4 introduces a set of semiotic and narratological categories for analyzing transmedia branding experiences and exemplifies them with the analysis of Burger King's McWhopper campaign in 2015. In the last section, the article introduces a series of reflections and proposals for future studies in this field.

\section{Transmedia storytelling}

According to Jenkins $(2003,2006)$ transmedia storytelling is a practice that emerges from the convergence of the media industry and collaborative cultures. Transmedia stories "are stories told across multiple media. At the present time, the most significant stories tend to flow across multiple media platforms" (Jenkins et al. 2006: 86). User-generated contents are an essential component of any transmedia storytelling experience. Blogs, social media, wikis, and fanfiction platforms should be considered open-source story-creation machines that make it possible for users to enrich the narrative world (Bruns 2008; Scolari 2009, 2013). As it can be seen, a transmedia narrative has two traits that characterize it: narrative expansion and participatory culture. The story is told through multiple media and platforms. The narrative 
may begin in a feature film or a novel, and continue in a television cartoon series, a comic, or a videogame, expanding the original plot with new characters and events. In addition, the fans also expand the narrative world with new contents and actions.

In the new media ecology audiences are more than fragmented: they are atomized into many screens, devices, media, and platforms. The business model of broadcasting is not sustainable anymore. In this context transmedia storytelling is a very useful strategy for building very loyal niches of consumers around a narrative world. In the old media ecology audiences were mediacentered, now, in the new media ecology, they are narrative-centered.

\subsection{Transmedia worlds}

Inspired by studies into cyberworlds, researchers like Klastrup and Tosca (2004) have introduced the concept of the "transmedia world":

Transmedial worlds are abstract content systems from which a repertoire of fictional stories and characters can be actualized or derived across a variety of media forms. What characterizes a transmedial world is that audience and designers share a mental image of the "worldness" (a number of distinguishing features of its universe). The idea of a specific world's worldness mostly originates from the first version of the world presented, but can be elaborated and changed over time. Quite often the world has a cult (fan) following across media as well. (Klastrup and Tosca 2004: 409)

A transmedia world differs from Jenkins' transmedia storytelling in that the latter "focuses on the concrete telling of one story through different media" while the former "is about the abstract properties that cut across the different manifestations" (Klastrup and Tosca 2004: 410). The core elements of transmedial worlds are:

- Mythos: establishing the conflicts and battles of the world, including the characters of the world; for example, the creation of Middle Earth and the different races as detailed by Tolkien.

- Topos: the setting of the world in a specific historical period and detailed geography; for example, Middle Earth, its languages, its poetry and traditions in The Lord of the Rings.

- Ethos: this is the explicit and implicit ethics of the world and (moral) codex of behavior that characters in the world are supposed to follow; for example, Tolkien's fight of good versus evil, and the exaltation of friendship (Klastrup and Tosca 2004: 409-410). 
These three properties of transmedial worlds are very useful for analyzing transmedia branding strategies. Before proceeding with the analysis of transmedia storytelling and branding the article will open a brief parenthesis and quickly review the relationships between brands and narratives.

\section{Towards transmedia branding}

A brand is perhaps the most perfect synthesis between the material and the symbolic world. Karl Marx had already detected commodity fetishism in the midnineteenth century, and a few decades later branding was born to differentiate standardized products. Now, at the beginning of the twenty-first century, it could be said that commodities have liquefied into storytelling containers that convey them through a narrative world (Scolari 2008).

According to semioticians like Floch (2001) and Semprini (1993, 1996, 2013) a brand always tells a story and conveys a series of values. Subjects are free to choose which story/brand they like: if the subject does not accept the values proposed by the narrative of brand $\mathrm{A}$, he or she may find the values of brand $\mathrm{B}$ or $\mathrm{C}$ more attractive. If the subject feels in tune with the story and admires the values of a particular brand, it may be said that a semiotic contract has been signed between the brand and the subject. Following this line of thought, the entire market appears as a symbolic space where each company or institution tries to impose its own storytelling and values, trying to seduce subjects and make them sign the semiotic contract. If a company presents itself by appealing to values such as freedom and rebellion, to differentiate themselves their competitors should articulate other narratives based on other values, such as sustainability and saving. Storytelling is a useful tool for differentiating a company's particular position in the symbolic market and retaining customers by offering a set of shared values. Until the 1950s advertising campaigns were product-centered, they then gradually became more and more user-centered, and now brands are a narrative-centered experience (Scolari 2008, 2015).

\subsection{From transmedia storytelling to transmedia branding}

If transmedia storytelling is a narrative told across multiple media and platforms with the collaboration of users, and a brand is a series of symbolic traits and values expressed by the narrative that identifies one good or service as 
distinct from the others, then transmedia branding is a brand narrative told across multiple media and platforms with the collaboration of users. Like any other branding experience, the final objective of a transmedia branding strategy is to convey a series of unique and distinctive values in the context of an overloaded symbolic market. Transmedia branding stands out as one of the best strategies in a media ecology characterized by the explosion of new media and platforms, the fragmentation of audiences and the emergence of usergenerated textual production. The age of broadcasting "is clearly dead and we are not just dealing with an audience, but an audience of audiences. This requires new techniques and processes. The solution lies in the substance of the corporate story world" (Berkson 2012: par. 1). According to Jeff Gomez, one of the most successful transmedia producers in the US, at today's fragmented digital frontier:

\footnotetext{
Stakeholders must design their properties to play uniquely and compellingly on different media platforms, so the point of entry into the brand or story world can come from almost any direction through any medium. By creating a consistent and ever-growing canon and maintaining brand integrity, you will reinforce your relationship with your audience, building lasting brand loyalty, and potentially an evergreen franchise. The best way to accomplish this is the technique of transmedia storytelling. (Gomez 2012: par. 20)
}

A transmedia branding strategy should not only focus on the "canon," that is, the official expansion of the storytelling through different media and platforms, but also, like in transmedia fictional storytelling, on promoting user engagement, including spaces for user participation.

\section{Transmedia branding: a semio-narratological approach}

\subsection{A semio-narratological approach}

The crossover between storytelling and branding is not precisely new: semioticians like Floch (2001) and Semprini (1993, 1996, 2013) were already analyzing brands in the 1990s from a semiotic perspective. In recent years, the increasing interest in storytelling and branding has expanded the analytical tools available in this field (Danesi 2006; Ferraro 2002; Marrone 2007; Remaury 2007; Rossolatos 2015; Salmon 2008; Volli 2016). 


\subsubsection{Semiotic approach}

From a semiotic perspective, the brand can be defined, simultaneously, as a vector of meaning, a value, and a contract. the identity of the brand is the result of these three operations (Semprini 1996).

This process ... contributes to making us live in a world that we perceive as ordered, categorized and endowed with meaning. The brand takes on, in this context, an important role as a device that distributes values of common images of a range of products, controls their strength, constructs lines of connection and lines of separation between various entities. (Ferraro 2002: 173, author translation)

How is brand meaning constructed? From a generative perspective Floch (2001) recognizes three levels:

- Deep level (or axiological level): space where abstract elements relate and oppose each other (freedom/repression, urban/rural, man/woman, work/ entertainment, etc.). These elements often do not appear on the surface of the brand's discourse: they stay in the nucleus of its universe of meaning and guarantee that the discourse is consistent over time.

- Narrative level: the basic elements are narrativized, they are organized into action sequences. The narrative program developed by Greimas (1987) is an abstract formula that represents an action that consists of a temporal succession of states embodied by a series of actants (Subject, Object, Sender, Receiver, Helper, and Opponent). During this process the Subject has to handle a series of "instruments" and pass a series of tests that qualify them as a "competent subject" and allow them to overcome the obstacles before reaching the desired Object.

- Discursive level: in this level the narrative sequences are spatialized, actorialized, temporalized; they are defined in detail and take on a particular specific character. The existence of basic narrative structures allows different "versions" to be created working at the discursive level and periodically renovating the communicational production without affecting the constitutive values (which reside in the deep level).

- Manifestation level: some semioticians include this fourth level (Semprini 1996; Marrone 2007) as an extension of the third level. In the manifestation level the different texts emerge and integrate the "brand mix" (i.e., spots, graphic pieces, stores, apps, etc.). This is the level where transmedia strategies are expressed.

How is this path presented in a traditional advertising product? The classic Marlboro campaigns submerge the consumer in a world based on a series of abstract elements (freedom, man, pleasure, rural life, work, etc.) that differentiate it from other narrative worlds (for example, other brands of cigarettes oppose this 
universe and emphasize urban values or free time and entertainment). At the narrative level there is a "self-made cowboy" who works hard on rural activities and, at the end of the day, after finishing his "mission," smokes a Marlboro. At a discursive level, it is possible to see the cowboy from an external point of view in different situations and framings; the cowboy is situated in a specific time (twentieth century) and space (the American wild territory). Finally, at a manifestation level, these narrative structures are expressed in different communication products (spots, photographs, slogans, etc.). It can even happen that the fundamental values of the Marlboro world do not appear in the iconic message or in the linguistic message: these values are often incorporated in the visual language (the frame, point of view, colors, sizes, etc.) or in visual or verbal rhetorical figures that generate complicity with the readers (Joly 1993).

The construction of meaning is a "contractual process" in which the "strategy of the author" confronts the "strategies of the readers" (Eco 1979). Beginning from the elements displayed by the enunciator in the text, the reader contributes to the production of meaning by adding their experiences and applying their interpretive competencies. Brands are not foreign to this interpretive dynamic and the game that is set up between author and reader:

\footnotetext{
A brand never enunciates its own values directly, they are included within more or less structured narrations, inside which the values can become activated and develop all their meanings ... A brand doesn't enunciate its values, it tells a story ... [and] by telling stories it constructs possible worlds and claims a territory, substance and content for its values. (Semprini 1996: 135-137, author translation)
}

In summary, by means of a narrative the brand is presented as a vector of meaning that contains a set of values and at the same time proposes a contract to its consumers/readers. In transmedia branding, this narrative expresses itself in different media and platforms (manifestation level). Two elements should be highlighted: brands surround the consumer/reader in a discursive universe that gives shape to a possible world with its own values and rules. However, the narrative nature that these worlds take on allow the researcher to describe the production of meaning by means of a journey that starts from fundamental and abstract oppositions, crosses the narrative level, goes through the discursive level and expresses itself in the manifestation level.

\subsubsection{Narratological approach}

Remaury (2007) proposes an anthropological approach to brands that is very close to the semiotic approach described above, and which also includes an 
analysis of the narrative. in this context remaury proposes six types of brand narratives:

- Time-based narrative: includes foundational ("the first one" like Levi's, Gillette) and legendary past-recuperation of a pre-industrial "golden age" (e.g., beers) stories.

- Place-based narrative: includes geographical myths of origin (e.g., wine from La Rioja, prosciutto di Parma) or narratives about a promised land (political or religious narratives).

- State-based narrative: includes state-centered stories (childhood in the case of McDonald's, youth in Coca Cola) or passage-centered stories (the narrative presents a transformation that involves a transition from old to young, from fat to thin, etc., like in anti-wrinkle creams or diet products).

- Character-based narrative: includes stories centered on archetypes (characters represent values, like the Marlboro man) or real-life incarnations (celebrities like Steve Jobs or Giovanni Rana).

- Expertise-based narrative: includes stories focused on craftsmanship (in this case the legitimacy relies on the producer, e.g., "home-made food") or the product expertise (the expertise is in the product, like in IKEA's easy to put together furniture).

- Material-based narrative: includes stories about high-tech artificial products (clothes, shoes, etc.) or natural and original products "from nature."

This approach is very useful for looking at and understanding the sense construction "instructions" that emerge from the textual contents and that make the narrative work. Questions that can be answered through this approach are, for example: How does the brand differentiate itself from its competitors? How does the transmedia branding campaign expand through different media and platforms? And how does the brand interpellate its main "enemy"? After this brief presentation of analytical models, we will now explore a transmedia branding strategy.

\subsection{Mcwhopper, a transmedia branding campaign}

To promote World Peace Day on 21 September 2015, Burger King US called for a "burger wars ceasefire" with their long-standing rival McDonald's. Via a full-page open letter published in The New York Times and The Chicago Tribune, as well as out-of-home billboards, the Miami-based company proposed that they and McDonald's set aside their historical differences and join forces. The campaign also included a couple of YouTube videos published on 26 August 2015 and a 
series of posts on social media. ${ }^{1}$ The output of this truce would be the "McWhopper," a peace-loving burger that combined all the tastiest ingredients from the McDonald's Big Mac and Burger King's Whopper.

Beyond the full-page open letters and the out-of-home billboards, the campaign centered on a website (www.mcwhopper.com) where users could view the full Burger King "peace agreement" and send in all kinds of proposals, from packaging suggestions to recipe ideas. Burger King suggested selling the peace burger for one day only (Sept. 21) in one location, a "pop-up restaurant" that would be situated in Atlanta (midway between McDonald's HQ in Chicago and its own in Miami) and would include specifically designed hybrid packaging and staff uniforms. All earnings of the operation would benefit Peace One Day, a non-profit organization that was founded in 1999. As McDonald's did not accept the proposal, Burger King was overwhelmed with responses from other QSR food brands across the globe, like Denny's, Wayback Burgers, Krystal, and a Brazilian chain called Giraffas. Burger King accepted these offers and created the "Peace Day Burger," a hybrid burger only available on World Peace Day. McDonald's rejection of the proposal was published on their Facebook wall.

In the few hours after the campaign began, thousands of DIY McWhoppers were made by people around the world and shared via social media and global news broadcasts. The McWhopper for Burger King campaign achieved over 7.6 billion impressions, more than USD $\$ 144$ million in earned media, and a substantial $40 \%$ increase in Peace Day awareness (Campaign Brief 2015). It was the most awarded campaign at the 2016 Cannes Lions, the prestigious international festival of creativity: the campaign received a total of 17 lions. The campaign also picked up six Yellow Pencils, one Wood Pencil, and one Graphite Pencil in the D\&AD Awards in London (Young and Rubicam New Zealand 2015; Burns 2015; Ruddick 2015).

\subsection{Transmedia branding campaign: a semio-narratological analysis}

As already indicated, the semiotic approach to narrative describes the sense production process as a sequence of levels that researchers must reconstruct to understand how the "meaning machine" works.

1 Burger King McWhopper Proposal: https://www.youtube.com/watch?v=e01a4-ClcTs; Burger King The McWhopper Sandwich Proposal: https://www.youtube.com/watch?v= DsaUulj6Xb0. 
- Deep level (or axiological level): the McWhopper campaign can be situated in a traditional value conflict that moves thousands of stories: peace against war. In semiotic analysis the application of Greimas' semiotic square is a basic tool for representing this struggle and expanding the positions (Greimas 1987). As it can be seen, the opposition between war-peace situates the conflict McDonald's versus Burger King into the position of war. Burger King's peace proposal moves it from war to truce, a momentary (but not definitive) reconciliation between the two adversaries.

McDonald's rejection of the offer rolls the situation back to war. However, the acceptance of the proposal by other possible “enemies," like Denny's, Wayback Burgers, Krystal, and Giraffas, and the continuation of Burger King's campaign after McDonald's rejection, keeps the brand on the "right" side (peace - truce) as well as keeping the possibility alive of a second and definitive movement from truce to peace.

- Narrative level: The McWhopper campaign follows a simple narrative pattern: a Subject (Burger King) has an Objective (to make peace with its traditional “enemy"). This narrative program has an Opponent (McDonald's) but counts on the support of different Helpers (firstly the consumers, but also other fast food companies like Denny's, Wayback Burgers, etc.). In this specific case Burger King also occupies the actancial position of the Sender, while the Receiver (the actant that benefits from achieving the connection between the subject and the object of desire) is the consumers. McDonald's rejection meant that they did not take up the position of Helper, a more positive role than being the opponent of Burger King's "peace agreement." In this alternative positioning, the Opponent would have been the "war" between fast food companies, which is in fact a common enemy to all such companies. However, McDonald's decided to take on the role of Opponent and refused the "peace agreement," thus acquiring negative values. The instruments, the tools that support the action of the Subject towards the Objective, are the videos published on YouTube by Burger King, explaining when, how, where, and why to participate.

- Discursive level: in this level the narrative sequence has a voice situated in a specific space and time. Semiotic analysis distinguishes between the enunciator of an utterance and the enunciatee to whom it is addressed. In the McWhopper campaign the enunciator is clearly Burger King, and the enunciatee, McDonald's. This second company is being directly interpellated by the former (dialogic rhetoric model according to Adam 2005). Let's see how it works in the first paragraph of the open letter: 
An open letter from Burger King to McDonald's

Good morning, McDonald's.

We come in peace. In fact, we come in honor of peace. We know we've had our petty differences, but how about we call a ceasefire on these so-called "burger wars"?

Here's what we are thinking.

In this paragraph different discursive movements can be identified. In the beginning the "we" only refers to Burger King ("we come in peace") but immediately after it refers to the two companies ("we've had our petty differences"), to return to the exclusive we at the end ("here's what we are thinking"). In the second and third paragraphs the enunciator describes the proposal (explicative rhetoric model according to Adam 2005) without abandoning the exclusive "we" ("we'd like to propose ..."):

Peace One Day is a non-profit organization campaigning to make Peace Day, September 21, an annual day of global unity. They have a powerful rallying call - "Who will you make peace with?" - which has inspired us to lead by example and extend an olive branch of our own. We'd like to propose a one-off collaboration between Burger King and McDonald's to create something special - something that gets the world talking about Peace Day.

The McWhopper.

All the tastiest bits of your Big Mac and our Whopper, united in one delicious, peace-loving burger. Developed together, cooked together and available in one location for one day only Peace Day, 21 September 2015, with all proceeds benefiting Peace One Day. All we need from you is a fez McDonald's crew members to help combine your ingredients with ours.

We appreciate that's a lot to swallow, so we've created mcwhopper.com to give you a better understanding of our proposal.

Let's end the beef, with beef.

Talk soon.

The final statement of the "peace agreement" to McDonald's indirectly includes an invitation to consumers ("we've created mcwhopper.com to give you a better understanding of our proposal"). The website, for its part, followed the open letter enunciation interpellation model ("MCD's, welcome to our McWhopper proposal") but supported by graphic elements and videos. However, to push user participation the website included a "Recipes" section to directly interpellate consumers:

To get you excited about the mouth-watering possibilities of the McWhopper, we've put together a short "burger build proposal" using an equal number of ingredients from each of our signature burgers.

The videos that supported the campaign were aligned to the values and narrative of the textual pieces but explored different enunciations. In the 
Burger King / McWhopper Proposal (26 August 2015) ${ }^{2}$ animation video a voiceover explains the proposal. The discourse is neutral, the enunciator uses the third person ("So, Burger King is proposing a burger war cease-fire to join forces with McDonald's on Peace Day and create the McWhopper”), but immediately after, the voice introduces the first person ("We could rattle a bucket, but buckets aren't loud”). This "we” expands to Jeremy Gilley, founder of Peace One Day, in the following scene, and finally the voice brings all of them together ("We can't do this without them," "All we have to do is park our differences for one day and do what we both do best"). From a rhetorical perspective, the descriptive model prevails in the beginning and moves to an explicative one in the second part of the video. The animation video explains the basic facts (how, where, why, who) of the proposal.

The second video (Burger King / The McWhopper Sandwich Proposal; 26 August, 2015) ${ }^{3}$ is a didactic explanation, with no voice-over, of how to combine the different components to create a real McWhopper. It does not fully explain the whole proposal, so this video could be considered as a paratext (Genette 1997) of the other one (the consumer needs to watch the other video or read the open letter to understand it).

McDonald's rejection of the proposal was published in their Facebook wall:

Dear Burger King,

Inspiration for a good cause ... great idea.

We love the intention but think our two brands could do something bigger to make a difference.

We commit to raising awareness worldwide, perhaps you'll join us in a meaningful global effort?

And every day, let's acknowledge that between us there is simply friendly business competition and certainly not the unequaled circumstances of the real pain and suffering of war.

We'll be in touch.

- Steve, McDonald's CEO

P.S. A simple phone call will do next time.

McDonalds' answer to Burger King's proposal goes from the exclusive we ("We love the intention") to the inclusive we ("between us there is simply friendly business competition," "we'll be in touch"). It also includes direct interpellations to the competitor ("A simple phone call will do next time”).

2 https://www.youtube.com/watch?v= e01a4-ClcTs

3 https://www.youtube.com/watch?v= DsaUuIj6Xb0 
The McWhopper campaign also included other audiovisual productions, for example a time-lapse short video (Burger King Peace Day Event; 16 October, 2015) ${ }^{4}$ that shows the construction of the one-day restaurant with the support of five brands (Burger King, Denny's, Giraffas, Krystal, and Wayback Burger) and the five out of the 1,500 possible hybrid burgers that were made and distributed for free. The number of viewers of this video (less than 8,000 one year after the campaign) confirms that the big impact was obtained with the other videos (1.7 M and 0.7 M views one year after the campaign).

- Manifestation level: In this level it is possible to identify the different media and platforms involved in the transmedia strategy. Advertising was maybe the first professional sector that adopted, many decades ago, a strategic approach to transmedia storytelling: the textual expansion was carefully designed by a professional team and not the result of a chaotic process of reacting to the media environment (but rather a tactical approach to transmedia; Scolari 2013). From a transmedia perspective, the "canon" of this campaign encompassed newspapers (the open letter), billboards, YouTube videos, and other social media. It was also reported on traditional media, such as television, and the proposal spread on the social media. According to the producers the campaign 'resulted in one of the most talked about advertising campaigns of 2015, delivering over US\$100 million worth of free media in the U.S. alone. Every media story and social media post further raised awareness of the forthcoming World Peace Day (Young and Rubicam New Zealand 2015).

From Remaury's perspective, it could be said that as "fastness" is not a differential trait of fast-food companies anymore, they have to explore other narrative models; for example, focusing on the quality of the product (materialbased narrative), the know-how (expertise-based narrative) or, sometimes, developing a character-based narrative (e.g., Ronald McDonald), or focusing on children (state-based narrative). The McWhopper campaign proposed an innovative state-based narrative that included a movement from war to peace. The 2015 McWhopper initiative could be compared to Burger King's slogans in 2006 "Eat like a king. Not a clown" or "You're no clown with the Crown" to see the difference: then there was a discursive "state of war" between the two companies. Changing the state for at least one day brought Burger King's narrative closer to the discourse of organizations like Peace One Day.

From the perspective of "transmedial worlds" (Klastrup and Tosca 2004) the McWhooper campaign includes the following elements:

4 https://www.youtube.com/watch?v=s0D90DQYCBM 
- Mythos: after decades of comparative advertising, Burger King's "peace agreement" should be considered to be a small revolution in the highly competitive fast-food market. The fight for differentiation is hard and this tactical move (truce for one day) opens a new dimension for future proposals.

- Topos: The "pop-up restaurant" situated in Atlanta, just in the middle between McDonald's HQ in Chicago and Burger King's own in Miami, reinforced the sense of truce and neutrality.

- Ethos: Burger King's proposal ("We come in peace," "All we have to do is park our differences for one day and do what we both do best") and McDonald's refusal clearly situated the two actors in the ethic plane. The rapid response of other companies - not directly involved in the original call for action - who wanted to join the McWhopper proposal confirmed which was the right move to make.

Before concluding the analysis, a couple of reflections on user-generated contents and other (para)textual expansions. While narratologists and semiotics have theorized on fictional worlds for decades (Eco 1979), the experience of "living" and "participating" in a narrative-world brand has been expanded by the arrival of new media platforms based on user-generated contents (Van Dijck 2013). Now consumers, already transformed into textual prosumers, can enrich the official narrative world by creating brand new or remixed texts. Like any other text, user-generated contents can be analyzed following the same semionarratological approach already applied to official contents. For space reasons it is not possible to develop this part of the analysis in this article, but usergenerated contents created around the McWhopper narrative (e.g., the "unboxing" videos produced by a consumer and shared on YouTube) ${ }^{5}$ should be included in any semio-narratological analysis of transmedia branding.

The intertextual networks created around transmedia narrative worlds are almost infinite. For example New York Post journalist Tim Donnelly, inspired by the McWhopeer operation, proposed 10 funny mashups (Apple + Microsoft $=$ Apple Word, Time Warner + Walmart $=$ WarMart, SeaWorld + Subway $=$ SubWorld, Taco Bell + Doritos $=$ Nacho Cheese Doritos Locos Tacos, etc.). These kinds of textual contributions are also part of the transmedia storytelling textual environment; they contribute to the circulation of the narrative and expand the "coverage" of the narrative-world brand (Donnelly 2015). Like any other expansive textual network, it is not difficult to see where a transmedia branding narrative starts, but it is impossible to see where it ends.

5 BK Peace Day Burger Unboxing: https://www.youtube.com/watch?v=lb6QiCHrWkI 


\section{Conclusions}

If traditional advertising was product-centered, and in the second half of the twentieth century adopted a user-centered approach, in the present day a hegemony of narrative-centered media experiences is emerging. According to Codeluppi (2001), since the 1980s, advertising has entered into a new phase defined as "meta-advertising":

Advertising is increasingly self-conscious of its own language and history. Its object is no longer the product but rather, more and more, itself, its discourses and communication mechanisms. In revealing the secrets of its inner device, advertising seeks to establish a relationship of complicity with the consumer. (Codeluppi 2001: 20, author translation)

The self-reflection on Burger King's traditional "war" with McDonald's and the complicity contract with consumers, in the context of a transmedia strategy that involves traditional and new collaborative media, makes the McWhopper campaign a refined example of meta-advertising. In this context, a semio-narratological approach could be a useful tool not only for analyzing transmedia branding strategies but also for designing these strategies. As Floch (2001) put it, this approach facilitates the intelligibility, the pertinence and the differentiation of a branding strategy. In a transmedia environment, messages should stay consistent as they travel through the different media and platforms; some contradictory enunciational operations in the Burger King discourse, for example the use of the "we" in different ways, could have been improved by using a semio-narratological approach during the campaign design. The pertinence, understood as the search for the invariable in the branding discourse, worked smoothly in the McWhopper campaign: there was a strong graphic connection between the different media (newspapers, billboards, videos). The difference is the key element: in an overcrowded media ecology (too many media, too many texts) introducing a difference is essential. In this sense, the mutation from war to peace introduced a break in a symbolic environment characterized by a tradition of hard competition between the fast-food actors. It was easy for consumers and other media to recognize the initiative, talk about it and spread it even more through the social media with the complicity of the users.

In other words: the semio-narratological approach considers brands to be transmedia narrative worlds that can be analyzed, designed and managed like any other transmedia storytelling construct in the field of fiction. Recovering research on transmedia fictional strategies (more than one decade old) and combining it with semio-narratological analytical (and design) tools would enrich the field of transmedia branding and facilitate the development of innovative strategies in this field. 


\section{References}

Adam, Jean-Michel. 2005. Les textes types et prototypes: Récit, description, argumentation, explication et dialogue. Paris: Armand Colin.

Berkson, Alan. 2012. Brands, narratives, and story worlds - part 1. Intelligent Catalyst, October 18. http://blog.intelligistgroup.com/brands-narratives-and-story-worlds-part-1/ (accessed 16 October 2016).

Campaign, Brief. 2015. Y\&R’s Burger King “McWhopper” campaign: How a big idea from little New Zealand went global (interview to Tom Paine). Campaign Brief December 31. http:// www.campaignbrief.com/ (accessed 16 October 2016).

Bruns, Axel. 2008. Blogs, Wikipedia, Second Life, and beyond: From production to produsage. New York: Peter Lang.

Burns, Will. 2015. McDonald's chooses pride over peace with Burger King's McWhopper offer. Forbes. September 1. http://www.forbes.com/sites/willburns/2015/09/01/mcdonaldschooses-pride-over-peace-with-burger-kings-mcwhopper-offer/\#50977857c4fa (accessed 16 October 2016).

Codeluppi, Vanni. 2001. Il potere della marca: Disney, McDonald's, Nike e le altre. Turin: Bolllati Boringheri.

Danesi, Marcel. 2006. Brands. New York \& London: Routledge.

Donnelly, Tim. 2015. 10 mashups we need more than a McWhopper. New York Post, August 26. http://nypost.com/2015/08/26/10-mashups-we-need-more-than-a-mcwhopper/ (accessed 16 October 2016).

Eco, Umberto. 1979. The role of the reader: Explorations in the semiotics of texts. Bloomington, IN: Indiana University Press.

Ferraro, Guido. 2002. La pubblicità nell'era di Internet. Roma: Meltemi.

Floch, Jean Marie. 2001. Semiotics, marketing, and communication. London: Palgrave Macmillan.

Genette, Gerard. 1997. Paratexts: Thresholds of interpretation. New York: Cambridge University Press.

Gomez, Jeff. 2012. The 10 commandments of twenty-first century franchise production. Business Insider, October 19. http://www.businessinsider.com (accessed 16 October 2016).

Greimas, Algirdas. 1987. On meaning: Selected writings in semiotic theory. Minneapolis: University of Minnesota Press.

Jenkins, Henry. 2003. Transmedia storytelling: Moving characters from books to films to video games can make them stronger and more compelling. Technology Review, January 15. http://www.technologyreview.com/Biotech/13052/ (accessed 16 October 2016).

Jenkins, Henry. 2006. Convergence culture: Where old and new media collide. New York: NYU Press.

Jenkins, Henry, Katie Clinton, Ravi Purushotma, Alice Robison \& Margaret Weigel. 2006. Confronting the challenges of participatory culture: Media education for the twenty-first century. Chicago, IL: MacArthur Foundation.

Joly, Martine. 1993. L'introduction à l'analyse de l'image. Paris: Nathan.

Klastrup, Lisbeth \& Susan Tosca. 2004. Transmedial worlds: Rethinking cyberworld design. In Proceedings of the 2004 international conference on cyberworlds, 409-416. Washington: IEEE Computer Society.

Marrone, Gianfranco. 2007. Il discorso de la marca: Modelli semiotici per il branding. Bari \& Rome: Laterza. 
Remaury, Bruno. 2007. Brands and narratives: Brands and the cultural collective unconscious. Paris: Editions de l'Institut Français de la Mode, Editions du Regard.

Rossolatos, George. 2015. Handbook of brand semiotics. Kassel: Kassel University Press. Ruddick, Graham. 2015. Burger King continues quest for Peace Day burger after McWhopper rejection. The Guardian, September 1. https://www.theguardian.com/business/2015/sep/ 02/burger-king-peace-day-burger-mcdonalds-mcwhopper (accessed 16 October 2016).

Salmon, Christian. 2008. Storytelling, la machine à fabriquer des histoires et à formater les esprits. Paris: Découverte.

Scolari, Carlos A. 2008. On-line brands: Branding, possible worlds, and interactive grammars. Semiotica 169(1/4). 169-188.

Scolari, Carlos A. 2009. Transmedia storytelling: Implicit consumers, narrative worlds, and branding in contemporary media production. International Journal of Communication 3. 586-606.

Scolari, Carlos A. 2013. Narrativas transmedia: Cuando todos los medios cuentan. Barcelona: Deusto.

Scolari, Carlos A. 2015. Transmedia storytelling: Brands, narratives, and storyworlds. In George Rossolatos (ed.), Handbook of brand semiotics, 151-169. Kassel: Kassel University Press.

Semprini, Andrea. 1993. Marche e mondi possibili: Un approccio semiotico al marketing della marca. Milan: Franco Angeli.

Semprini, Andrea. 1996. La marca: Dal prodotto al mercato, dal mercato alla società. Milan: Lupetti.

Semprini, Andrea. 2013. La marca postmoderna: Potere e fragilità della marca nelle società contemporanee. Milan: Franco Angeli.

Van Dijck, Jose. 2013. The culture of connectivity: A critical history of social media. Oxford, UK: Oxford University Press.

Volli, Ugo. 2016. Semiotica della pubblicità. Roma \& Bari: Laterza.

Young \& Rubicam New Zealand. 2015. McWhopper: The world's most talked about burger. http://yr.co.nz/portfolio-item/mcwhopper/ (accessed 16 October 2016). 